\title{
Technological options towards a carbon neutral town in central Italy
}

\author{
Andrea Bartolini ${ }^{*}$, Danilo Salvi ${ }^{1}$, Leonardo Pelagalli ${ }^{1}$, Flavio Caresana $^{I}$ and Gabriele Comodi ${ }^{1}$ \\ ${ }^{1}$ Università Politecnica delle Marche, Via Brecce Bianche 12, Ancona, Italy
}

\begin{abstract}
The paradigm of highly integrated cross sector energy systems grants several opportunities for welcoming high shares of renewable energy sources in meeting the energy demands of current urban districts. A key asset towards such challenge lies in the progressive deployment of more distributed energy systems, achieving configurations tailored to the needs of the local communities lying in their physical proximities.

This study analyses the case study of a small town situated in central Italy, which energy supply already features a set of distributed and cross-sector energy resources such as a district heating network fed by a 1.2 MWe natural gas engine and more than $30 \mathrm{MWp}$ of non-controllable renewables.

The city energy systems are modelled in the analysis tool EnergyPLAN in order to analyse the technical feasibility of introducing different technological options aimed at reducing the polluting emissions generated in meeting different energy related needs of the district.
\end{abstract}

\section{Introduction}

In order to meet the impelling challenge to curb emissions and more towards a more sustainable society [1] there are several options and approaches which leverage both the trend of increasingly decentralized energy systems and the rapid ascent of renewable energy sources and energy storage technologies [2]. Another significant shift in energy consumption lies in the expected uptake of electric vehicles (EV) [3], which will entail a radical shift of energy demands towards an increased request of electricity, but also the potential of using the same EVs as grid-balancing assets through advanced smart charging and discharging schemes [4]. This also happens in a scenario with increasingly distributed and interconnected energy conversion and distribution infrastructure, that could potentially meet different energy-related commodities requested by communities in a holistic approach that can be summarized under the concept of smart multi-energy systems $[5,6]$. These type of systems are intrinsically very complex given the number of variables at stake and phenomena that are to be correctly accounted for during an energy systems planning phase [7].

It has, in fact, been proved by several authors that a holistic analysis approach to energy planning allows harnessing the most benefits from such complex systems, but most importantly is mandatory while analysing systems with very high non-controllable RES penetration $[8,9]$.

This study proposes the analysis of a real test case of a small town situated in central Italy, which already has a significant penetration of non-controllable renewable energy sources (RES) by means of PV systems.

A model of the town is built and simulated in the EnergyPLAN energy systems analysis model [10] in order to assess the feasibility of high RES energy supply towards carbon neutrality, building on previous work on the same test case by the authors [11].

The analyses consider all the energy requirements of the city such as electricity, heat for space heating and sanitary hot water production, transport and natural gas, achieving a holistic approach. The $\mathrm{CO}_{2}$ neutrality is studied considering both increased RES penetration and a diverse set of flexibility providing assets: both on the supply and demand side.

In particular, with regards to the transport sector, the full electrification of the local vehicle fleet is studied by also considering the potential impact of advanced charging/discharging capabilities of the vehicles such as vehicle-to-grid (V2G), which could potentially have a significant impact in helping to welcome high shares of RES.

\footnotetext{
*Corresponding author: a.bartolini@univpm.it
} 


\section{Materials and Methods}

This section described the case study that is analyzed, the software tool used to perform the analyses, and the scenarios that are investigated.

\subsection{The Osimo test case}

\subsubsection{Available data}

Osimo is a small town of approximately 40,000 inhabitants situated in central Italy. Through distribution networks, the city has access to both electricity and natural gas, which are managed by a municipal energy company. Moreover, the same company operates a hightemperature district heating network $\left(75^{\circ} \mathrm{C}-95^{\circ} \mathrm{C}\right.$ supply temperature depending on the season), which is currently fed by a $1.2 \mathrm{MWe}$ natural gas engine, a $35 \mathrm{kWe}$ high-temperature heat pump and 13.5 MWth of natural gas boilers.

The local RES capacity is divided into a set of different assets: a $100 \mathrm{~kW}$ of electricity production system from energy recovery from water pressure drops, approximately $31 \mathrm{MWp}$ of PV, which belongs to both rooftop installations (both households and commercial activities) and also in large installations in fields. An aerial view of the city, together with a sample of typical PV systems configuration is shown in Figure 1. Furthermore, there is a $1 \mathrm{MWe}$ biogas CHP plant, that impacts the energy needs of the city only by producing electricity, as all the recovered heat is used to sustain the chemical digestion process.

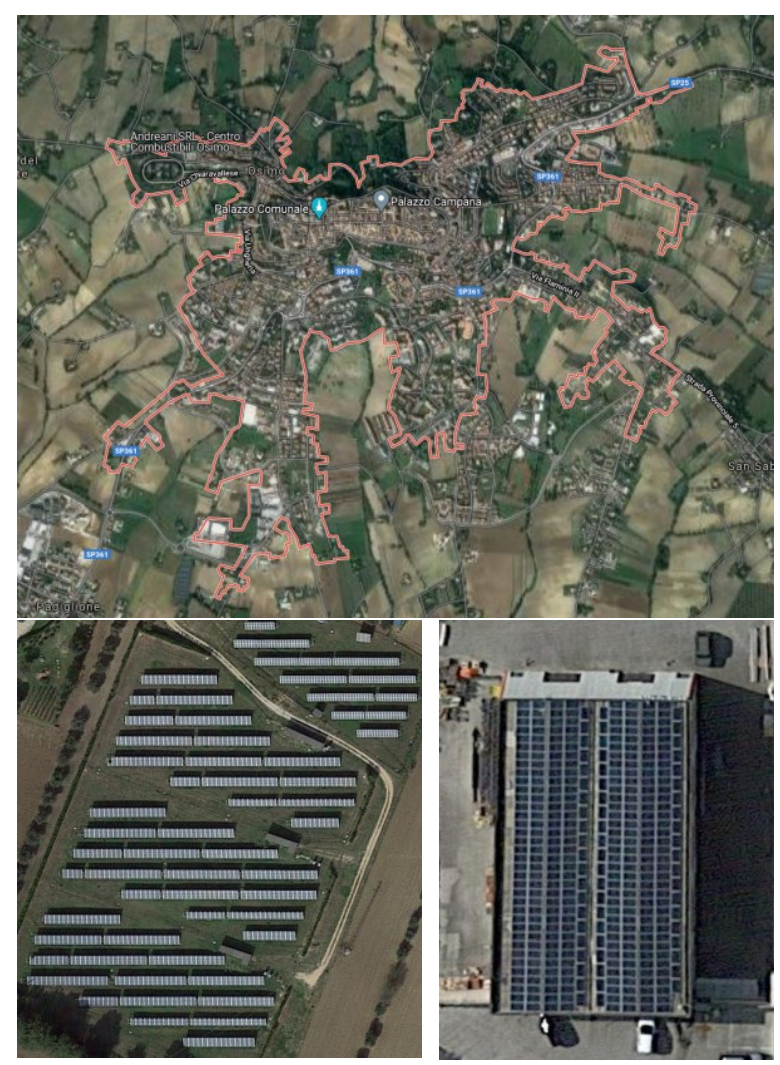

Figure 1 - Osimo aerial view \& typical field/rooftop PV systems configuration
From a modelling standpoint, the city of Osimo can be thought as a distributed multi-energy system, which is also a microgrid given the single point of connection with the Italian electricity transmission grid. A graphical conceptualization, taken from previous work by the authors [11] of the microgrid with all its assets, is shown in Figure 2.

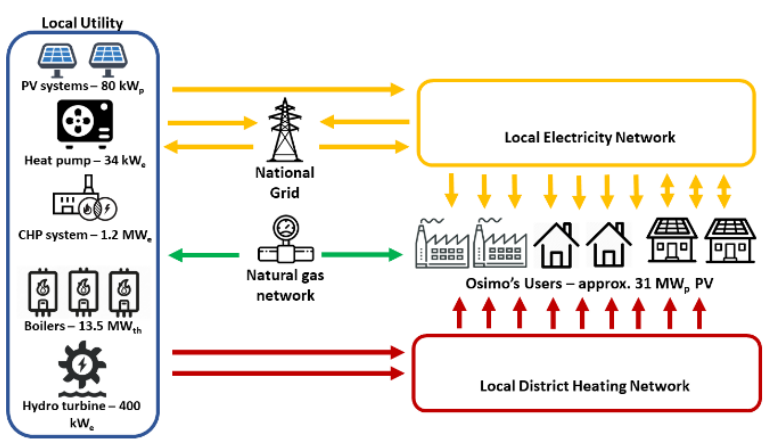

Figure 2 - Graphical conceptualization of the Osimo multienergy system [11].

With regard to the year 2018, a set of hourly measured data is available. This refers to both the heating demand of the users supplied by the DHN and the electricity exchanges with the transmission grid, both positive during withdrawal and negative while injecting surplus of non-controllable electricity produced by means of PV systems. These are shown in Figure 3 and Figure 4 respectively in terms of the average total daily quantities for each month of the year.

The available data of the local PV systems refers to a set of systems that are directly owned and monitored by the municipal company, for a total capacity of $80 \mathrm{kWp}$. From high resolution data the specific daily averaged electricity production of such systems in 2018 is shown in Figure 5.

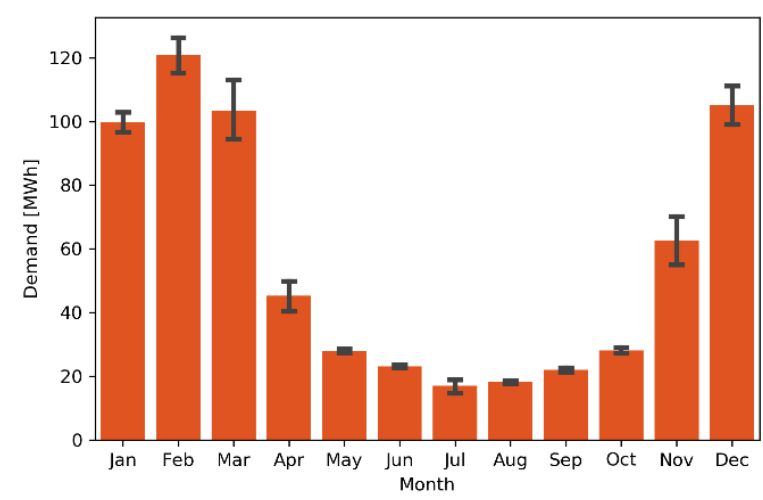

Figure 3-Average total daily demand for the district heating network across the year 2018. 


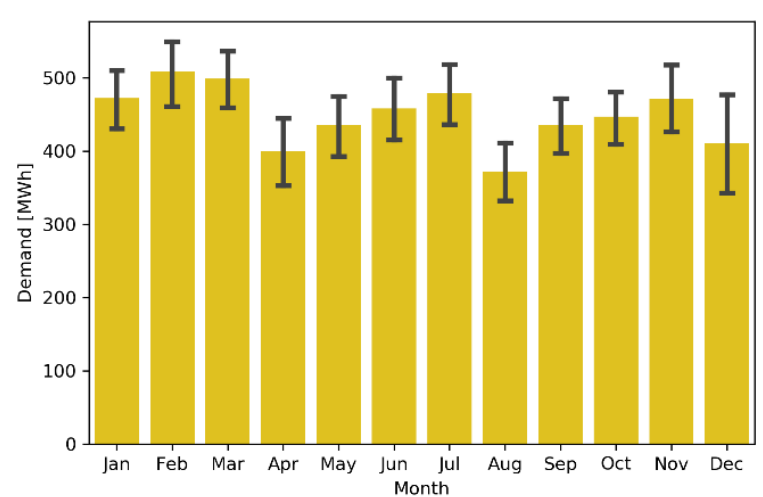

Figure 4 - Average total daily electricity exchanges with the national transmission grid across the year 2018.

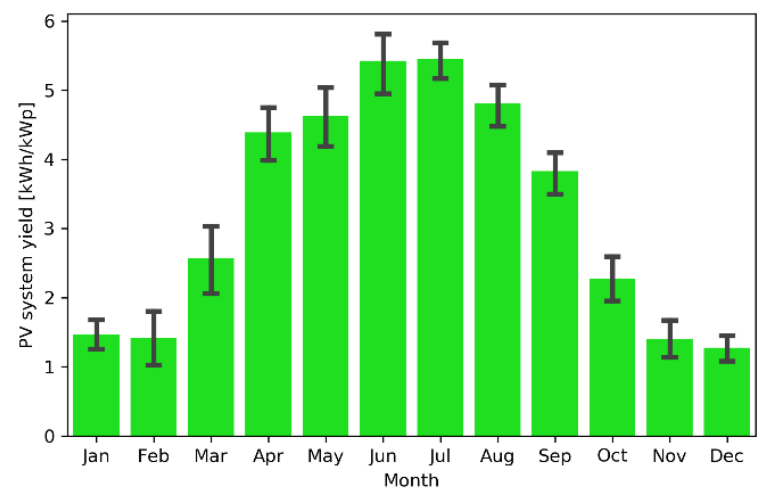

Figure 5-PV system average total daily yield across the year 2018.

Furtherly, additional data is available regarding the total amount of natural gas that is supplied to customers for end uses in industrial processes and individual heating solutions. The yearly totals, of the DHN supplied heat, the electricity withdrawn from and injected to the transmission grid, and finally the natural gas demand are shown in Table 1.

\begin{tabular}{|lc|}
\multicolumn{1}{c}{ Commodity } & Year $\mathbf{2 0 1 8}$ \\
\hline DHN heat & $20.3 \mathrm{GWh}$ \\
\hline Electricity withdraw & $124.4 \mathrm{GWh}$ \\
\hline Electricity injection & $4 \mathrm{GWh}$ \\
\hline PV system yield & $1,180 \mathrm{kWh} / \mathrm{kWp}$ \\
\hline Natural gas demand & $220 \mathrm{GWh}$ \\
Table 1 - Summary statistics of consumption and RES \\
production in Osimo in 2018
\end{tabular}

The total $\mathrm{CO} 2$ emissions that represent the situation as it is now are computed by using the provided measured data. Both the emissions generated by burning natural gas (to feed the DHN and by the individual users) and the ones generate by withdrawing and feeding electricity into the national grid are accounted for. The latter in particular are computed by the following formula:

$$
C O_{2_{\text {grid }}}=\left(\frac{E_{\text {grid }}^{+}}{\eta_{\text {grid }}}-E_{\text {grid }}^{-} * \eta_{\text {grid }}\right) * c_{\text {grid }}
$$

Where $\mathrm{CO}_{2}$ grid is the total amount of $\mathrm{CO}_{2}$ emitted yearly by using the electricity grid, $E_{\text {grid }}^{+}$and $E_{\text {grid }}^{-}$are the total amounts of electricity in GWh withdrawn from and fed in back to the same grid respectively, $\eta_{\text {grid }}$ is the transmission efficiency of the grid, which is set to $95 \%$, and finally $c_{\text {grid }}$ are the $\mathrm{CO}_{2}$ emissions of the Italian electricity production system (considering both thermoelectric and other types of electricity generation), which is set to $0.308 \mathrm{kgCO}_{2} / \mathrm{kWh}$ of electricity [12].

Such emissions amount to approximately $129 \mathrm{ktCO}_{2}$ per year by considering the provided data for 2018, and will constitute a baseline to confront the analyzed scenarios with.

\subsubsection{Modelling of the natural gas demand}

In order to thoroughly investigate a full decarbonization of the energy supply for the city, considering a fully integrated energy system, an hypothesis is made on the current natural gas demand shown in Table 1. The available data to characterize such demand only allows to compute the share of it that is destined to residential and non-residential customers, which is approximately of $50 \%$ each.

With regard to the non-residential $50 \%$ of $110 \mathrm{GWh}$ in total, the assumption is that such demand can entirely be met by expanding the current DHN, which supplies heat at high temperatures. This is a simplistic assumption given the potential existence of industrial processes requiring heat at higher temperature levels but deemed acceptable given the absence of more detailed data. Such heat demand is added to the one currently characterizing the local DHN in the EnergyPLAN simulations. The demand is also increased by $20 \%$ to account for the network losses which were registered in the available 2018 data, leading to a total of $132 \mathrm{GWh}$ DHN demand.

The size of the CHP system is then increased across all the scenarios with respect to the current one. This is chosen to match the average increased heating demand (with the assumptions of Paragraph 2.1.3), which now is of $17 \mathrm{MW}_{\text {th. }}$ The electric and thermal efficiencies of the CHP engine are also modified to represent a larger and more efficient system and increased to $45 \%$ and $40 \%$ respectively.

The residential $50 \%$ is assumed to be entirely covered by air source heat pumps. This is also a simplistic assumption given that neglects the share of natural gas destined to uses like cooking, but which is deemed acceptable given the proportion of 20 to 1 of space heating demand vs home-cooking demand of heat in Italy [13]. In EnergyPLAN this is achieved by setting an individual heating demand and setting a reference average yearly COP that is used by the devices in meeting it. The reference COP for the heat pump is set to 4 , considering the yearly average temperature of $16^{\circ} \mathrm{C}$ for the city of Osimo [14]. 


\subsubsection{Modeling of the transport sector electrification}

The transport sector is considered within the simulations as an energy demand that could be entirely converted to electricity by means of a full replacement by plug-in and only battery electric vehicles (EV). By accessing a public dataset of the Marche region [15] (where Osimo is located) it's possible to obtain both the total amount of vehicles that are registered in the city, which as 2017 equaled approximately 26,000 cars [11]. Furthermore, the same dataset is used to classify the vehicles by their size, and to each size is assigned a specific electricity consumption in $\mathrm{kWh} / \mathrm{km}$ [16], which together with a yearly distance driven $[17,18]$ provides a total yearly demand for electric mobility of approximately $52 \mathrm{GWh}$ with a 100\% substitution of the current fossil-fired vehicles.

To properly simulate the presence of EVs it's also needed a temporal distribution of the charging process. This is obtained by referring to probability distributions of the charging process obtained by the literature [19], which are shown in Figure 6.

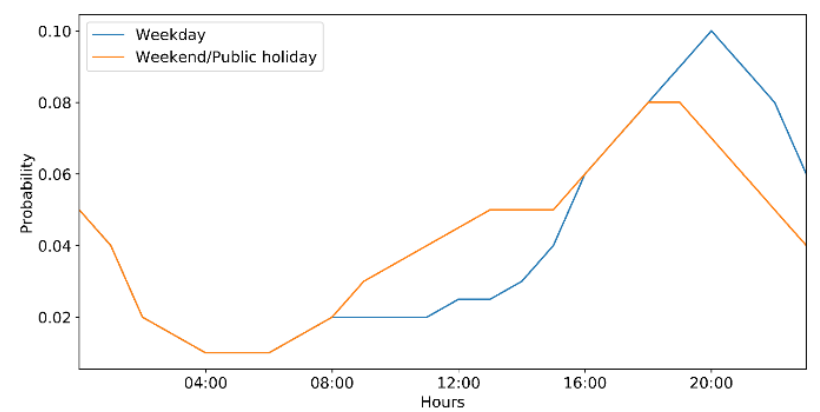

Figure 6 - Weekday and weekend behavior of the EV charging process.

The potential smart capabilities of EVs, both regarding smart charging and V2G, are modelled in EnergyPLAN by defining a set of parameters that refer to the whole fleet [20]. Such parameters represent model the availability of cars to be used as flexibility providing assets by the local grid, their power connection capacity and efficiencies (both for grid-to-car and car-to-grid energy flows) and their total storage capacity. The parameters are defined as follows for the fleet in Osimo:

- Share of cars driving at peak hours: $20 \%$

- Share of grid-connected parked cars during peak hours: $75 \%$

- Total electricity connection capacity: $260 \mathrm{MW}$, considering $10 \mathrm{~kW}$ per EV

- Total battery storage capacity: $780 \mathrm{MWh}$ per EV

- Efficiency for the grid-to-car and car-to-grid power flow: $90 \%$

\subsection{EnergyPLAN model \& Investigated Scenarios}

In building the EnergyPLAN models to simulate the different scenarios some options with regards to energy systems have to be ruled out in order to account for the peculiarities of the case study. Concerning RES availability both wind and a significant supply of biomass are not viable and thus, only solar PV capacity is considered as a degree of freedom in increasing the deployed RES capacity.

A significant increase in non-controllable electricity production entails well-known problems regarding the stability of electric grids and thus, the results are also evaluated in terms of the self-consumption potential that can be achieved through different flexibility providing approaches, both on the demand and supply side. The combination of flexibility assets available to meet the high RES capacity defines a specific scenario, as follows.

Scenario 1 finds the PV system capacity that allows reaching the CO2-neutrality of the city, without considering any flexibility providing asset. Thus, in this Scenario no storage system is considered, the demands of the EVs are considered inflexible etc.

Scenario 2 adds a set of approaches for Demand Side Flexibility (DSF) such as a heat storage capacity for up to two days in the individual electric heating sector, a V2G scheme (as described in subsection 2.1.2) for the EVs, and a $10 \%$ flexibility on the city's yearly electricity demand. In particular in the latter is assumed that $10 \%$ of the total yearly demand in GWh can be modulated within a daily timespan, for a maximum of 18.6 MW, which is $10 \%$ of the annual average hourly electricity demand.

Scenario 3 adds the flexibility of the supply side instead. The first asset that is considered is a thermal heat storage integrated with the DHN, with the storage capacity sized for potentially a long term used at half the yearly DHN demand, for a total of $76 \mathrm{GWh}$. The second is a power-to-gas system by means of an electrolyzer, which produced hydrogen can be used as a fuel to feed the DHN alternatively by the CHP system o the boilers.

Finally, Scenario 4 combines the assets described in both Scenario 2 and 3 to achieve flexibility on both the supply and the demand side. The four scenarios can be briefly listed as follows:

$$
\begin{array}{ll}
\text { 1. } & \mathrm{PV} \\
\text { 2. } & \mathrm{PV}+\mathrm{DSF} \\
\text { 3. } & \mathrm{PV}+\mathrm{TES} / \mathrm{H}_{2} \\
\text { 4. } & \mathrm{PV}+\mathrm{DSF}+\mathrm{TES} / \mathrm{H}_{2}
\end{array}
$$

All the simulations are performed by EnergyPLAN by using a contemporary heat and electricity balancing strategy: the model will then try to balance electricity imports and exports by also optimally managing cross sector technologies such as CHP and the rest of the flexible assets available. The $\mathrm{CO}_{2}$ emissions of each scenario are computed by considering both the ones computed by EnergyPLAN, and the ones ascribable to the usage of the national transmissions grid (both for withdrawal and injection) with the formula described in Paragraph 2.1.1 


\section{Results}

The results are described by means several features of the simulated scenarios with respect to the reference case, being the situation as it is now.

Firstly, Table 2 reports the PV system size that allows the net-zero yearly $\mathrm{CO} 2$ emissions, the natural gas that is burned by $\mathrm{CHP} /$ boilers within the city during the simulated year, and the hydrogen that is produced by means of the local electrolysers in the scenarios that allow it.

Table 3 reports the yearly kt of $\mathrm{CO}_{2}$ emissions divided in three categories and how they contribute to achieving the goal of net-zero emissions for the city. These are the ones generated by using grid electricity, the ones that are offset by injecting green electricity into the same grid, and finally the ones that are generated locally by burning natural gas to feed the DHN heat demand (considering fossil fuels-fired transport for the reference case).

Finally, Figure 7 shows graphically the total yearly electricity imports and exports from/to the national transmission grid in GWh across the four scenarios and compared with the reference case. The figure aims at depicting the degree of unbalance between the noncontrollable RES electricity supply and how it changes according to different flexibility possibilities.

\begin{tabular}{l|c|c|c|c|c|}
\multicolumn{1}{c}{} & Ref. & Sc. 1 & Sc. 2 & Sc. 3 & Sc. 4 \\
\hline PV size & 31 & 273 & 269 & 272 & 275 \\
$\begin{array}{l}\text { [MWp] } \\
\begin{array}{l}\text { N. gas } \\
\text { burned }\end{array}\end{array}$ & 31.7 & 220.3 & 209. & 168. & 212.4 \\
$\begin{array}{l}\text { [GWh] } \\
\text { H2 } \\
\text { produced } \\
{[\text { GWh] }}\end{array}$ & & & 4 & 9 & \\
\cline { 2 - 6 } & & - & - & 0 & 0 \\
\cline { 2 - 6 }
\end{tabular}

Table 2 - PV system size and District methane burned across the four scenarios and the current situation (reference).

\begin{tabular}{|c|c|c|c|c|c|}
\hline $\begin{array}{l}\mathrm{CO}_{2} \\
\text { emissions } \\
\text { [kt] }\end{array}$ & Ref. & Sc. 1 & Sc. 2 & Sc. 3 & Sc. 4 \\
\hline Import & 37.3 & 22.9 & 2.9 & 22.9 & 3.2 \\
\hline Export & -1.1 & -67.9 & -45.6 & -67.9 & -46.5 \\
\hline District & 93.16 & 44.9 & 42.7 & 44.9 & 43.35 \\
\hline$\underline{\text { Total }}$ & $\underline{129.4}$ & $\underline{-0.09}$ & $\underline{-0.06}$ & $\underline{-0.08}$ & $\underline{0.02}$ \\
\hline
\end{tabular}

Table 3 - CO2 emissions by category across the four scenarios and the current situation (reference).

Table 3 indicates that reaching the $\mathrm{CO}_{2}$ neutrality is achievable and comparing it with Table 2 it's possible to state that the PV system capacity that allows so is approximately the same in all the scenarios: ranging from $269 \mathrm{MWp}$ in Scenario 2 to $275 \mathrm{MWp}$ in Scenario 4. Across all the scenarios there is always a considerable consumption of natural gas, that reaches its lowest value in Scenario 3, which is the one that only allows flexibility on the supply side. Hydrogen production on the other hand is not scheduled, as the model prioritizes using the grid to balance the non-controllable electricity flows. Prioritizing hydrogen could have surely lessened the emissions generated under the "district" category of Table 3 (by reducing the amount of used natural gas), but at the price of a more wasteful usage of the RES generate electricity, which under the hypotheses made can be injected in the national grid with no constraints.

All the PV system capacities obtained are considerably larger than the $31 \mathrm{MWp}$ currently feeding into the local electric grid; but it can be assumed that it would be potentially matched by leveraging both rooftops and surrounding fields, as already done. It must be noted though that the footprint needed for such additional capacity would inevitably impact the availability such field for agricultural purposes, other than potential aesthetics/environmental concerns.

Furthermore, an additional drawback of such heavy PV presence lies in the increased need to use the grid to mitigate the non-controllability of the electricity production. This happens across all the scenarios as shown in Figure 7, thus even considering the different flexibility providing approaches that are studied.

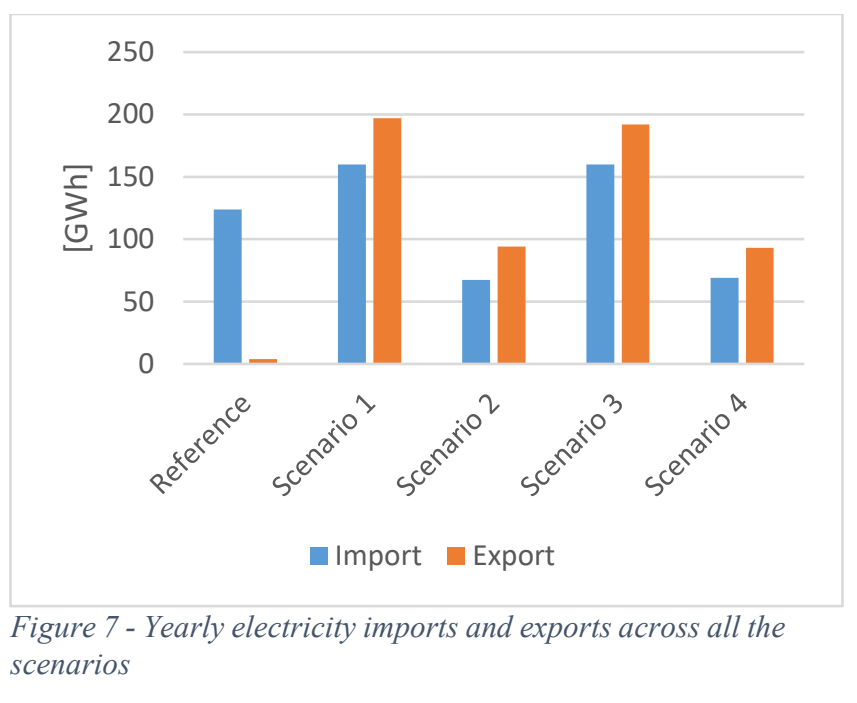

In particular, Figure 7 shows that the exports are the quantity that by far increases the most, and this is under the assumption that all of the exported electricity is actually used elsewhere, ultimately contributing to lower the $\mathrm{CO}_{2}$ emissions of the city according to equation (1). Export curtails due to grid congestion or instability issues in the transmission system and/or the city's own distribution system would in fact reduce such amount, getting the city back to being $\mathrm{CO}_{2}$ positive. From Figure 7 it's also possible to see that increasing the flexibility in demand is much more effective than the flexibility on the supply side, particularly thanks to equipping $100 \%$ of the vehicles within the city with V2G.

Given this scenario, there are also further options that could realize a more feasible $\mathrm{CO}_{2}$ neutral design for the city energy supply. First of all, the potential impact of energy efficiency is not yet considered, as the data representing the electricity and thermal demands is a 
fixed parameter across all the scenarios. Secondly, the impact of the progressive development of centralized hydrogen production on large scales, with the subsequent injection into the natural gas distribution network could lower the $\mathrm{CO}_{2}$ content of the distribution network's gas, contributing to lower the $\mathrm{CO}_{2}$ emissions of distributed CHP systems [21].

Furthermore, given the continuously dropping costs for PV a potential viable option could lie in an intentional overbuilding of the PV systems to obtain a steadier power generation profile, with the excesses of electricity being curtailed, a solution that it's already being proposed in the literature by some authors [22].

\section{Conclusions}

This study investigates a set of potential technological pathways to reach a $\mathrm{CO}_{2}$ neutral small city in central Italy, by using a real test case and leveraging a smart integrated energy systems approach.

A set of scenarios is studied to evaluate both the electrification of most of the city's energy needs, including a total electrification of the private transport sector, and an electricity supply relying predominantly on RES by means of PV systems. Each scenario considers a different degree of flexibility, considering approaches on both the demand and the supply side.

The results show that rendering the city $\mathrm{CO}_{2}$ neutral is theoretically feasible in all the scenarios by significantly increasing the local PV systems capacity, well beyond the current one. Other than the significant additional footprint required to host such systems, such heavy presence would be substantially impossible without heavily relying on the electric grid for balancing purposes, regardless of the different flexibility measures that are used within the city.

\section{References}

[1] United Nations. Transforming our World: the 2030 Agenda for sustainable Development. 2016. https://doi.org/10.1201/b20466-7.

[2] IRENA. Electricity storage and renewables: Costs and markets to 2030. 2017.

[3] Till Bunsen, Cazzola P, D'Amore L, Gorner M, Scheffer S, Schuitmaker R, et al. Global EV Outlook 2019 to electric mobility. 2019.

[4] Noel L, Zarazua de Rubens G, Kester J, Sovacool BK, Noel L, Zarazua de Rubens G, et al. The Technical Challenges to V2G. 2019. https://doi.org/10.1007/978-3-030-04864-8_3.

[5] Lund H, Østergaard PA, Connolly D, Mathiesen BV. Smart energy and smart energy systems. Energy 2017;137:556-65. https://doi.org/10.1016/j.energy.2017.05.123.

[6] Mancarella P. MES (multi-energy systems): An overview of concepts and evaluation models. Energy 2014;65:1-17.

https://doi.org/10.1016/j.energy.2013.10.041.

[7] Mavromatidis G, Orehounig K, Bollinger LA, Hohmann M, Marquant JF, Miglani S, et al.
Ten questions concerning modeling of distributed multi-energy systems. Build Environ 2019;165:106372. https://doi.org/10.1016/j.buildenv.2019.106372

[8] Mathiesen B V., Lund H, Connolly D, Wenzel H, Ostergaard PA, Möller B, et al. Smart Energy Systems for coherent $100 \%$ renewable energy and transport solutions. Appl Energy 2015;145:139-54. https://doi.org/10.1016/j.apenergy.2015.01.075

[9] Hansen K, Breyer C, Lund H. Status and perspectives on $100 \%$ renewable energy systems. Energy 2019;175:471-80. https://doi.org/10.1016/j.energy.2019.03.092.

[10] EnergyPLAN n.d. https://www.energyplan.eu/.

[11] Bartolini A, Comodi G, Salvi D, Østergaard PA. Renewables self-consumption potential in districts with high penetration of electric vehicles. Energy 2020;213:118653. https://doi.org/10.1016/j.energy.2020.118653.

[12] ISPRA. Fattori di emissione atmosfertica di gas a effetto serra nel settore elettrico naizonale e nei principali Paesi Europei. n.d.

[13] ENEA. Impatti energetici e ambientali dei combustibili nel riscaldamento residenziale. 2529.

[14] Wang R, Zhai X. Handbook of energy systems in green buildings. 2018 .

https://doi.org/10.1007/978-3-662-49120-1.

[15] Agenzia per l'Italia Digitale. Parco Circolante dei Veicoli - Regione Marche n.d.

https://www.dati.gov.it/dataset/parcocircolante-dei-veicoli-manutenzione.

[16] EVDB. Electric Vehicle Database n.d. https://ev-database.org/cheatsheet/energyconsumption-electric-car.

[17] Bellocchi S, Klöckner K, Manno M, Noussan $\mathrm{M}$, Vellini M. On the role of electric vehicles towards low-carbon energy systems: Italy and Germany in comparison. Appl Energy 2019;255:113848. https://doi.org/10.1016/j.apenergy.2019.11384 8.

[18] Unione Petrolifera. Previsioni di domanda energetica e petrolifera italiana 2019-2040. 1392.

[19] Element Energy. EV Charging Behaviour Study. 2019.

[20] Lund H, Kempton W. Integration of renewable energy into the transport and electricity sectors through V2G. Energy Policy 2008;36:3578-87. https://doi.org/10.1016/j.enpol.2008.06.007.

[21] European Commission. A hydrogen strategy for a climate-neutral Europe. vol. 53. 2015. https://doi.org/10.1017/CBO9781107415324.0 04.

[22] Perez M, Perez R, Rábago KR, Putnam M. Overbuilding \& curtailment: The cost-effective enablers of firm PV generation. Sol Energy 2019;180:412-22. https://doi.org/10.1016/j.solener.2018.12.074. 